\title{
DEFICITS IN THE APPLICATION OF ALUMINUM FOAM SANDWICH: AN INDUSTRIAL PERSPECTIVE
}

\author{
P. Hommel ${ }^{\otimes}$, D. Roth and H. Binz \\ University of Stuttgart, Germany \\ $₫$ patrick.hommel@iktd.uni-stuttgart.de
}

\begin{abstract}
Aluminum foam sandwich (AFS) is an innovative sandwich material for designing lighter products and has many advantages such as high stiffness and high mechanical-energy absorption capacity. Although AFS is ready for series production, the number of use cases is low. A survey was carried out in order to identify the obstacles in the application of aluminum foam sandwich. This paper presents the results of the survey, derives the demand for a support method for designing with aluminum foam sandwich and shows various support options to simplify the application of the material.
\end{abstract}

Keywords: lightweight design, design for $x$ (DfX), design methods, design guidelines, aluminum foam sandwich

\section{Introduction and motivation}

Realizing lightweight designs is a major challenge for which the various materials and construction methods are highly significant. One great potential for lightweight design lies in the use of sandwich materials (Beichelt, 2005), in particular aluminum foam sandwich (AFS), which consists of aluminum alloys in the face sheets and in the core (Banhart et al., 2017). The core consists of a porous foam structure, which is created by heating the raw material (Seeliger, 2011). Due to its manufacturing process, there is a metallic bond between the face sheets and the core. This bond does not require any adhesives and as a structure consisting of only one material, it has a high recycling quality (Seeliger, 2011). Further advantages of aluminum foam sandwich are its high bending stiffness at low density, good damping behavior and energy absorption properties (Sviridov, 2011). AFS components are therefore used in mechanical, plant and automotive engineering (Banhart et al., 2017), for example in battery boxes for electric vehicles (Schmerler et al., 2017; Havel, 2019; Hommel et al., 2019). Due to the high mechanical energy absorption of the aluminum foam, AFS is also suitable for use in crash-relevant components (Banhart et al., 2017).

Aluminum foam sandwich is available on the market (Seeliger, 2011) and is regarded as an innovative material with a great potential for application due to its diverse properties and possible applications (Binz et al., 2018; Sviridov, 2011).

To understand the needs of customers, identify obstacles to the application of aluminum foam sandwich and therefore increase the use of the material, a survey was conducted. This paper presents the results of the empirical survey on the use of aluminum foam sandwich from an industrial perspective. 


\section{Problem and goal}

Although aluminum foam sandwich has several advantages and many possible fields of application, the material is infrequently used in industry (Florek et al., 2014; Banhart et al., 2017), meaning that the number of industrial applications is below the potential of the material as confirmed by its various manufacturers. The reasons for obstacles to the application of AFS are not sufficiently known.

One possible reason for the low level of application is that design engineers have to face various challenges when designing with AFS. For example, these challenges result from a lack of known material parameters, and also from a lack of knowledge concerning the machining and joining possibilities of the material (Hommel et al., 2019).

To examine the demand for design support in industrial environments, a survey was conducted, the main objectives of which were to gain a better understanding of the obstacles to designing with aluminum foam sandwich and to identify the desired types of support. The main research questions of this article are therefore as follows:

1. What are the difficulties when using aluminum foam sandwich and what are the challenges in designing with aluminum foam sandwich?

2. Is support necessary for designing with aluminum foam sandwich?

3. How can the design with aluminum foam sandwich panels be supported (methodologically)?

\section{Structure of this paper}

In the following section, the "aluminum foam sandwich" material is described and the manufacturing and processing methods are presented. By presenting some of the material's advantages, different potential applications are highlighted. In addition, a survey on known obstacles to the application of metal foam is presented. Section 5 explains the structure of the survey by presenting individual blocks of questions and characterizes the respondents. The results of the survey are presented in Section 6 through various diagrams. In Section 7, the results are discussed. The article concludes with a summary of the results and provides an outlook for further activities.

\section{State of the art}

This section presents the state of the art concerning the manufacturing, benefits and applications of aluminum foam sandwich. At the end of this section, already known obstacles to the use of AFS are mentioned.

\subsection{Manufacturing}

There are many different methods for manufacturing metal foam (Banhart, 2018). The two main families for closed-cell foams are the powder metallurgy technique (Baumeister, 1990) and the melting metallurgy technique (Akiyama et al., 1987). Aluminum foam produced through the powder metallurgy technique has better mechanical properties than aluminum foam produced with the melting route, such as compressive strength. Therefore, aluminum foam sandwich made via the powder metallurgy route is more recommended for industrial applications than the other process (Orovčík et al., 2016).

In the powder metallurgy technique, aluminum powder and a foaming agent (usually titanium hydride $\mathrm{TiH}_{2}$ ) are mixed and compressed. By heating the aluminum foam above the melting temperature, the hydrogen gases out and the foam structure is formed. There are two common methods for the production of aluminum foam sandwich within the powder metallurgy route, the so-called AFS technology (Banhart and Seeliger, 2012; Baumeister et al., 1994) and the AAS technology (Schuller et al., 2017; Hohlfeld et al., 2018), which are presented in Figure 1.

In both cases, the aluminum foam is initially mixed with a blowing agent and compacted to produce a foamable core material. With the AFS technology, a container is formed from two face sheets of aluminum and the foamable core layer. This composite is rolled and can then be cut to size or formed. In the final step, the three-layered composite is heated and the foaming process begins (Seeliger, 2004). One advantage of this stable process is the possibility of fast heat input into the aluminum core due to the material bonding. However, one disadvantage is the high production effort caused by the 
complex rolling of foamable composites, meaning that this process is only economical for large batches (Hannemann et al., 2018; Schuller et al., 2017).

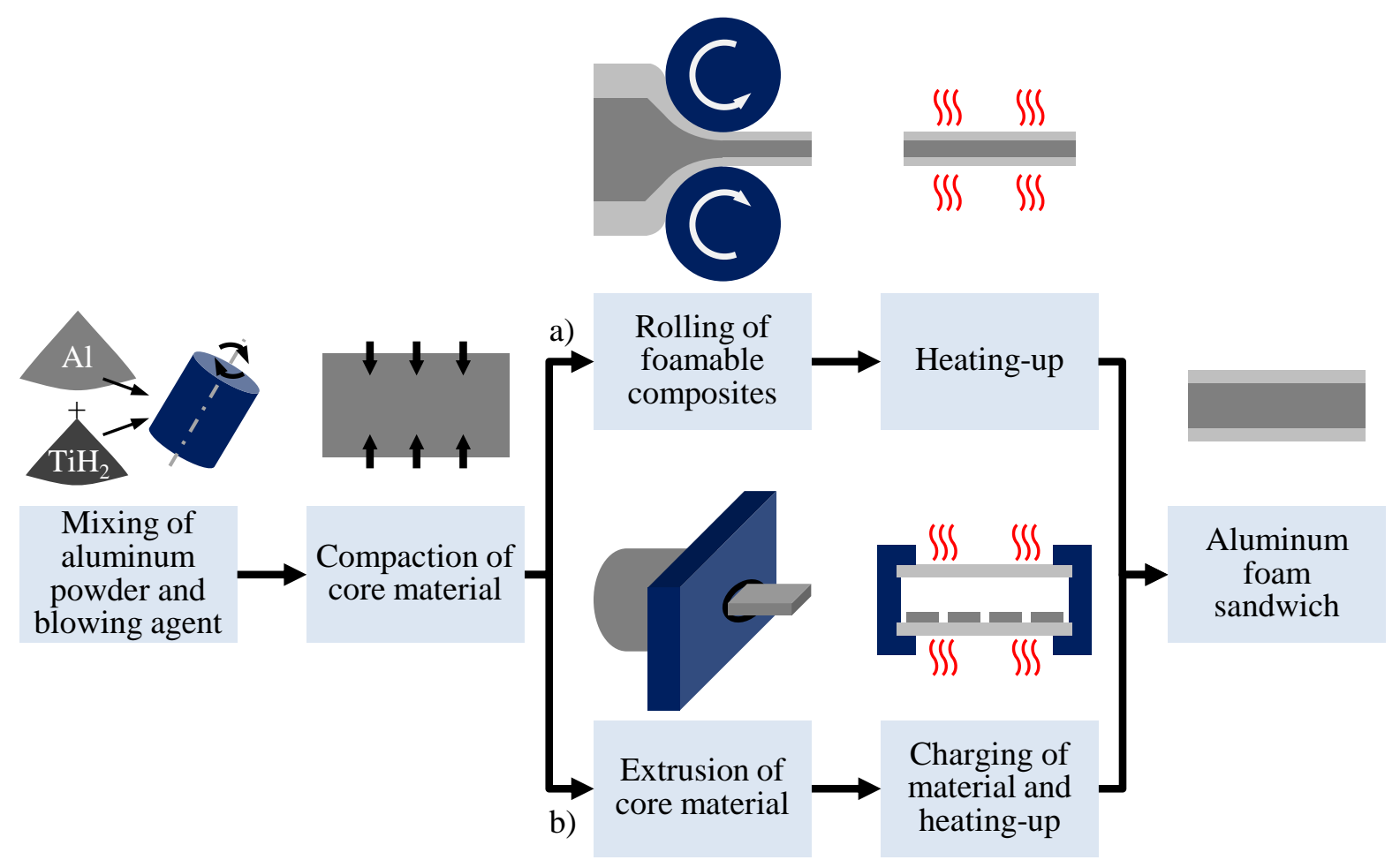

Figure 1. Manufacturing processes of aluminum foam sandwich: a) AFS technology, b) AAS technology, according to Sviridov (2011), Hohlfeld et al. (2018) and Hommel et al. (2019)

There is also the possibility of manufacturing aluminum foam sandwiches without rolling (Schuller et al., 2017). In this method, the core material is extruded and cut into several sheets. These sheets are placed between two face sheets, which are positioned at a certain distance. Finally, the foamable aluminum material between the two aluminum face sheets is foamed to form a sandwich (Hohlfeld et al., 2018). In addition to dispensing with rolling, another advantage is that the extrusion of the foamable material is simple (Hannemann et al., 2018). A particular disadvantage of this method is that the upper face sheet only comes into contact with the foam shortly before the end of the foaming process and that there is thus only a short time to build a strong connection (Hohlfeld et al., 2018).

As the panel-shaped material can be further processed using conventional sheet-metal processing methods, three-dimensional structures can be produced through cutting (sawing, milling, laser beam cutting) and joining (welding, gluing, screwing, riveting). Forming before or after foaming is possible, as is the foaming of different profiles. These opportunities afford the designer significant design freedom and allow the formation of complex shapes. (García-Moreno, 2016; Hommel et al., 2019; Metalfoam, 2016)

\subsection{Benefits and applications}

Aluminum foam sandwich differs from other sandwich materials, such as honeycomb sandwiches, because the layers do not have to be glued. Aluminum foam sandwich is therefore more heat-resistant, more weldable, fully recyclable and has better durability (Banhart et al., 2017). In addition to its high stiffness and low density, aluminum foam sandwich has other positive properties such as good energy absorption, increased mechanical damping and good sound-insulation properties (Sviridov, 2011). As aluminum foam sandwich effectively absorbs kinetic energy through deformation, it is suitable for applications where crash protection is required (Banhart et al., 1998; Havel, 2019; Nosko et al., 2010). Other applications like for example a sliding bed of a milling machine, a support of a working platform for a mobile crane vehicle, or a rocket in the aeronautical industry are shown in GarcíaMoreno (2016). 


\subsection{Obstacles}

Although there are many potential applications and some prototypes have been tested, the material is still rarely used in series production. Despite the aforementioned advantages, metallic foams are used less than honeycomb structures or polymer foams (Schüler, 2016). One reason for the lack of series application is the cost of the material (Florek et al., 2014). A further disadvantage is anisotropy and a large dispersion of the mechanical properties due to the inhomogeneities in the structure. These production-related disadvantages result in a low industrial acceptance (Nosko et al., 2010).

However, these are not the only obstacles. Hipke and Wunderlich (2000) conducted a survey on the obstacles to the use of metal foam, in which 121 respondents took part. The results of this survey are shown in Figure 2. Employees from the fields of research and development, design and calculation were interviewed. The main obstacles to the use of metal foam are the lack of technical parameters, the lack of reference applications, the cost and the availability of the material. The high cost and the low availability will improve with increasing acceptance, while action is required for the other obstacles. (Hipke and Wunderlich, 2000; Hipke, 2002)

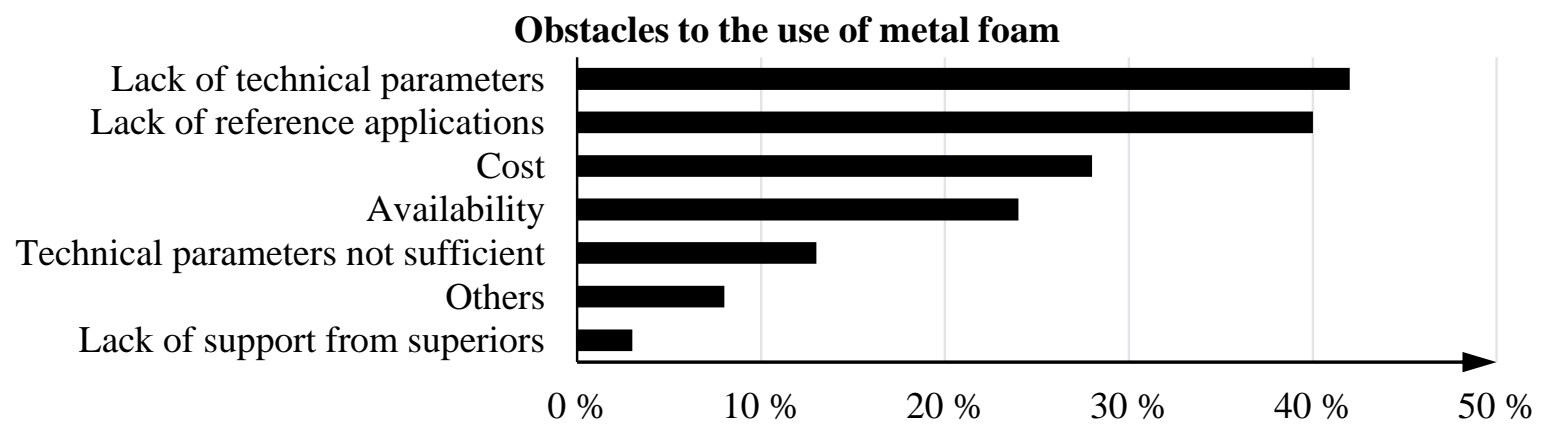

Figure 2. Obstacles to the use of metal foam according to Hipke and Wunderlich (2000)

Since this survey is already twenty years old, a question remains concerning the nature of the situation today. This paper therefore analyzes the current obstacles to the use of AFS and introduces possible ways to address these.

\section{Structure of the survey and description of the respondents}

This section explains the structure of the survey conducted by the authors, which deals with the use and possible applications of aluminum foam sandwich from an industrial perspective. The various question blocks of the survey are also mentioned and the respondents are characterized.

The survey on the use of aluminum foam sandwich was conducted online and was available between June and September 2019. The invitation to the survey was sent both to previous and potential future users of the material. The mailing list included various industrial companies of different sizes. In addition, the online link was passed on to interested trade visitors at a composite fair. A total of 571 invitations to the survey were distributed. In the invitation text and at the beginning of the survey, AFS was briefly presented to the participants by summarizing the most important properties and information of the material. This ensured that the participants focused on the correct material.

All questions in the survey were written exclusively in German to prevent misunderstandings during translation; therefore, all respondents were from German-speaking countries. The participants of the survey responded voluntarily. In order not to draw any conclusions about the test persons and not to have any influence on the answers, the survey was conducted anonymously and questions about gender and age were not given.

The survey included 36 questions in total, which were divided into three main sections as presented in Table 1. The questions examined various aspects such as awareness and reasons for using AFS, as well as obstacles to its use and the need for support in designing with AFS. The questions were presented as single-choice, multiple-choice or free-text. In all of the following diagrams on the singlechoice questions, the sum of the individual values may deviate from 100 percent due to rounding. In addition, the response options that were not ticked are not included in the diagrams. 
Table 1. Survey design

\begin{tabular}{|l|l|l|l|}
\hline & Section & Content & Number of questions \\
\hline 1 & $\begin{array}{l}\text { Demographics and } \\
\text { experience }\end{array}$ & Industry affiliation, work focus, company size & 8 \\
\hline 2 & $\begin{array}{l}\text { Lightweight design } \\
\text { and material usage }\end{array}$ & $\begin{array}{l}\text { Importance of lightweight design, importance and use } \\
\text { of different materials }\end{array}$ & 7 \\
\hline Areas of interest & $\begin{array}{l}\text { Awareness and } \\
\text { importance }\end{array}$ & $\begin{array}{l}\text { Awareness of the material and significance compared } \\
\text { to other materials }\end{array}$ & 4 \\
\hline $3 b$ & $\begin{array}{l}\text { Use of aluminum } \\
\text { foam sandwich }\end{array}$ & $\begin{array}{l}\text { Consideration in material selection, applications, } \\
\text { potentials, conflicts, challenges, obstacles }\end{array}$ & 10 \\
\hline 3c & $\begin{array}{l}\text { Requirements and } \\
\text { lack of information }\end{array}$ & $\begin{array}{l}\text { Requirements that would ensure increased application, } \\
\text { lacking information, lacking knowledge }\end{array}$ & 5 \\
\hline 3d & $\begin{array}{l}\text { Concluding questions } \\
\text { and final notes }\end{array}$ & $\begin{array}{l}\text { Further notes, other comments, offers, interest in future } \\
\text { contribution }\end{array}$ & 2 \\
\hline
\end{tabular}

Sixty-five persons participated in the survey. The work experience and the company size of the participants are evenly distributed, as can be seen in Figure 3: From small companies to large corporations, all groups are represented. The participants came from various industries with different work areas. The largest number of replies came from companies in the automotive sector $(51 \%)$ and mechanical engineering (37\%), with all other common sectors represented.

\section{How long have you been working} (in years)? $\mathrm{n}=65$

0 to 1

Above 1 to 3

Above 3 to 5

Above 5 to 10

Above 10 to 20

Above 20

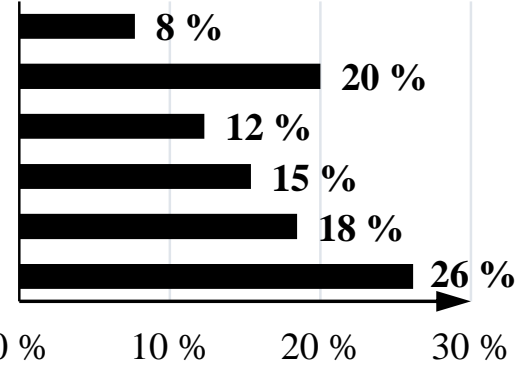

How many employees work for your company worldwide? $\quad \mathrm{n}=65$
1 to 9

10 to 49

50 to 249

250 to 999

1,000 to 9,999

10,000 to 49,999

50,000 or more
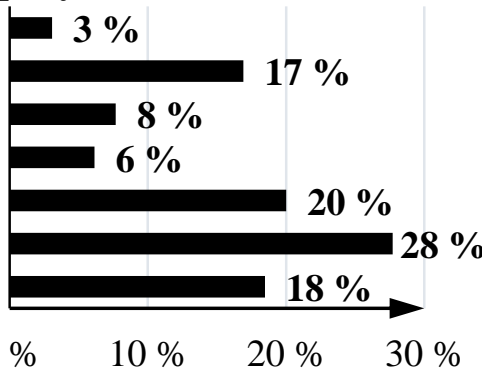

Which industry does your company belong to? (Multiple answers possible) $n=65$

Automotive

Mechanical engineering

Machine components

Others

Research institute

Service provider/consulting

Garden- and landscape-maintenance machines

Construction and building-services engineering

Machine tools

Tool and fixture construction

Other machinery

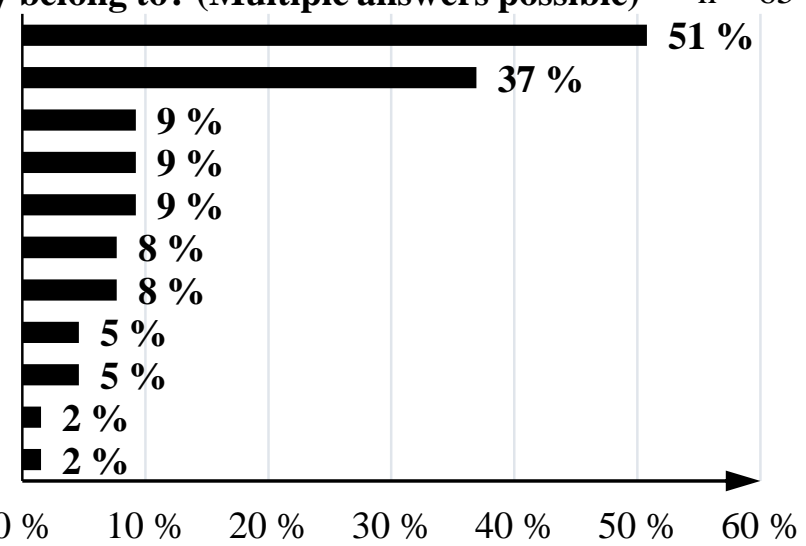

Figure 3. Work experience (top left), company size (top right) and industry affiliation (bottom) of the participants

The main work focus is on research and development $(65 \%)$, construction (43\%) and project management $(15 \%)$ and participants correspond to various hierarchy levels within the respective company. Employees right up to management took part in the survey. The majority of respondents $(55 \%)$ were employees without management or leadership responsibility. 
Figure 4 lists the lightweight materials most commonly used by the respondents of the survey. While almost all participants use aluminum, aluminum foam sandwich is currently only used by $18 \%$. Aluminum foam without face sheets is only used by $6 \%$. Compared with other materials, especially other sandwich materials such as honeycomb sandwich, less widespread industrial application is discernible.

Which lightweight materials/constructions do you use? (Multiple answers possible) $n=65$

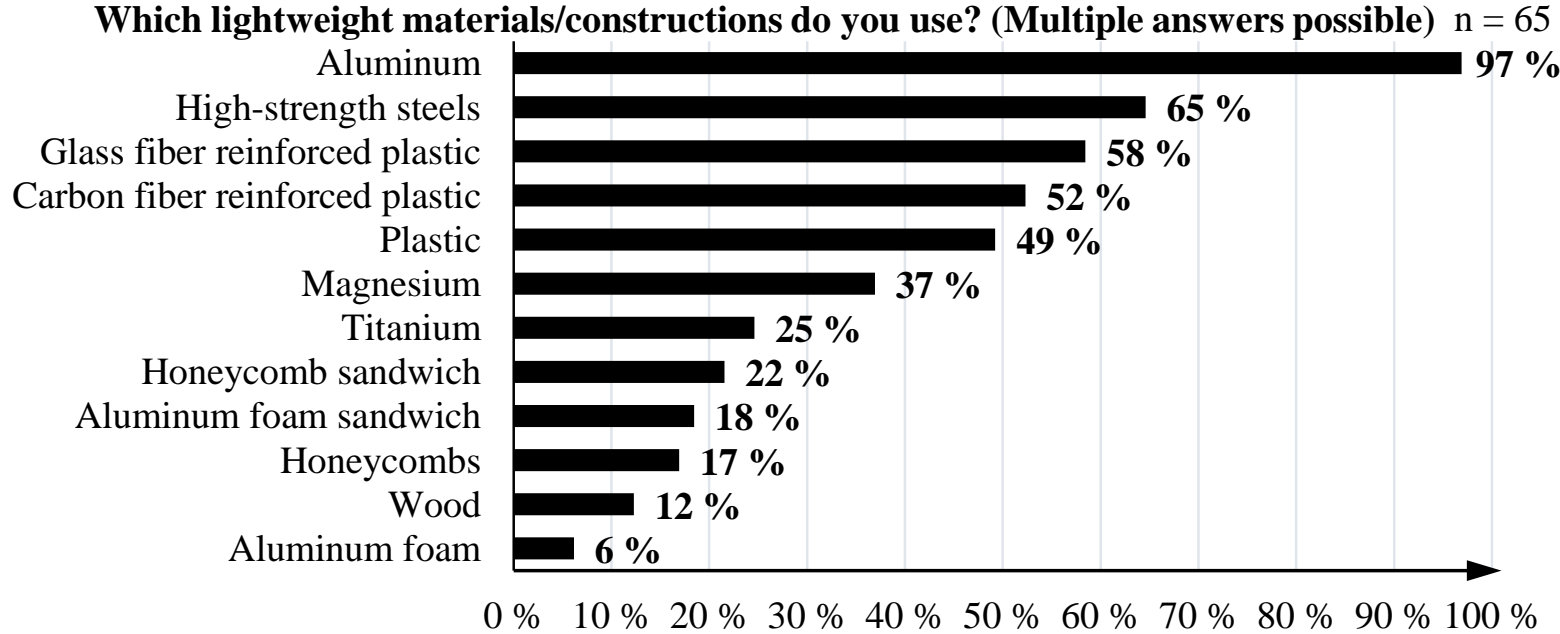

Figure 4. Use of various materials by participants

\section{Findings}

In this section, the main results of the survey concerning the application of aluminum foam sandwich are presented. Firstly, participants were asked if they knew of AFS before the survey, or whether it was the first time that they had heard of it. Figure 5 shows that half of the participants $(51 \%)$ were very familiar with the material, while $38 \%$ had at least heard of it. Only $9 \%$ did not know of the material before the survey.

Did you know of the material "aluminum foam sandwich" before this survey? $\mathrm{n}=65$

Yes, I am very familiar with the material

Yes, I've heard of it, but I don't know any characteristics

No, I was totally unfamiliar with the material

No information possible

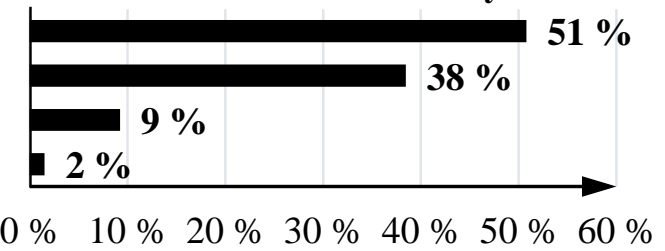

Figure 5. Familiarity of the participants with aluminum foam sandwich

In total, $89 \%$ said that they knew of the material, although only around half of all respondents (49\%) included AFS in their material selection at all. $42 \%$ answered that the use of the material was not being considered at all. Only about a quarter (26\%) of the respondents used AFS in current or previous projects, while $69 \%$ did not use the material. These results are shown in Figure 6.

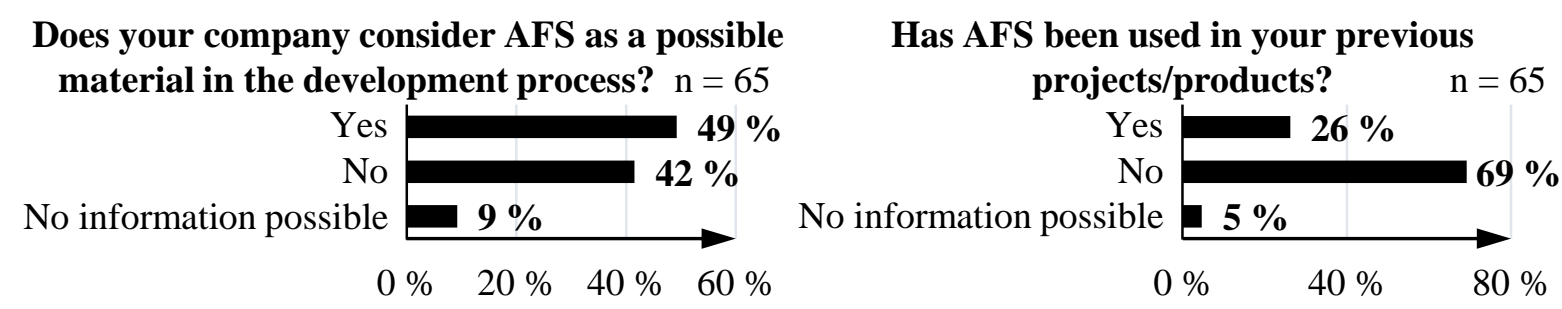

Figure 6. Consideration of aluminum foam sandwich in material selection (left) and previous usage of aluminum foam sandwich (right) 
The question therefore remains concerning why most of the participants have never used the material before or even considered it when selecting materials for construction. To answer this, respondents were asked in a free-text question about the reasons for the material not being considered, nor ever used. They often remarked that they were not fully familiar with the material or had a lack of experience with it. In addition, many participants were not aware of any applications, so they did not know where the material could be used most appropriately. The cost is another aspect that is seen as critical, as well as the lack of design knowledge. It is mentioned that the introduction of force into the sandwich is difficult and the possibilities of joining technology are unknown. Furthermore, the material characteristics are insufficient, unknown or have an excessive dispersion. Therefore, the material maps are of inadequate quality, which leads to insufficient simulation results.

After the participants were generally asked about the reasons for not considering the material, they were asked in a further question about the obstacles they see with the use of aluminum foam sandwich. These two aspects were deliberately asked separately in order to gain the best possible understanding of the current situation. To answer the question about the obstacles, they had a number of choices from which they could choose. The results are shown in Figure 7. The most frequent answer, which $58 \%$ of the respondents gave, was the high cost of the material. Roughly every second respondent $(51 \%)$ also stated that they perceive the lack of design knowledge of the material to be an obstacle. Lack of reference applications (40\%), unknown material (32\%) and insufficient $(29 \%)$ or lacking ( $25 \%)$ technical parameters were further answers. These answers also coincide with the free-text question mentioned above and are therefore a good indication that nothing has been omitted.

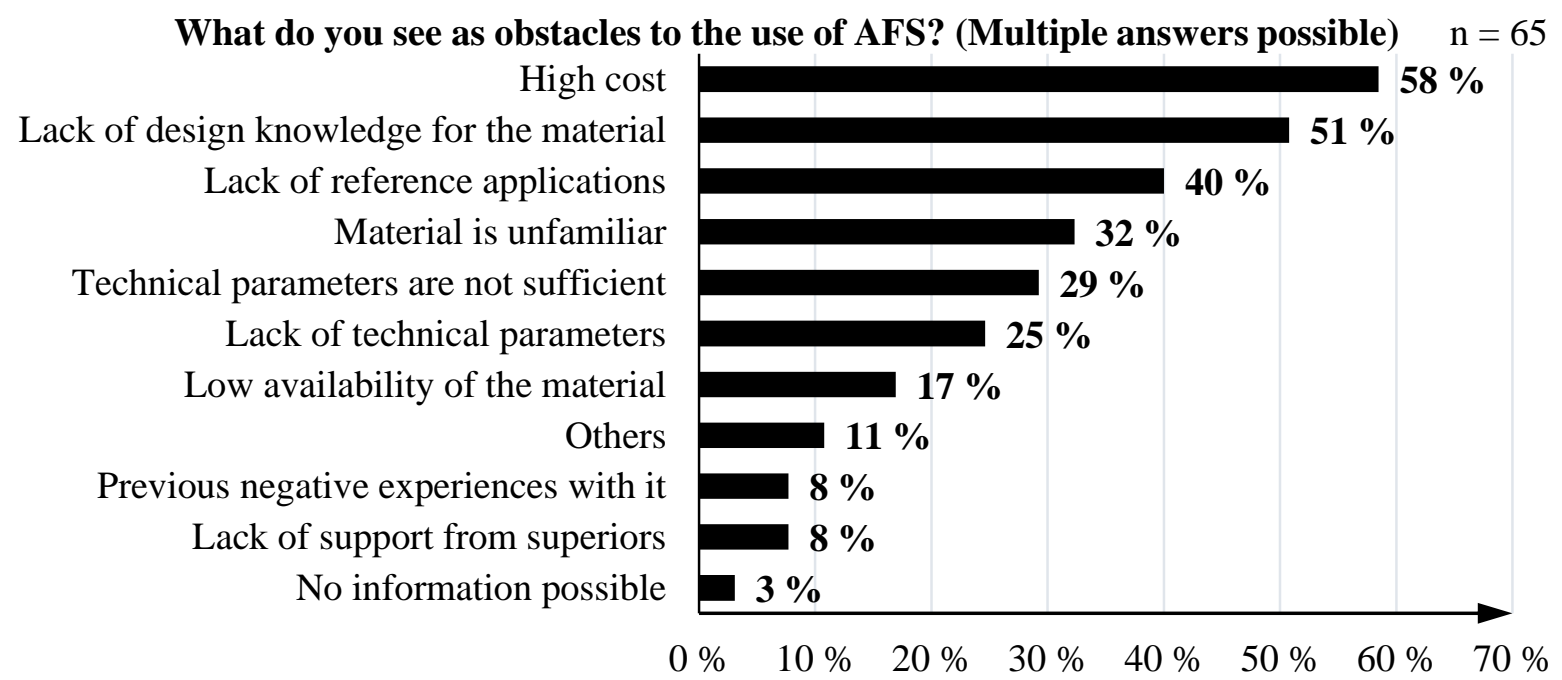

Figure 7. Obstacles to the use of aluminum foam sandwich

After having asked about obstacles to the use of AFS, the last part of the survey concerned the requirement for a support method for designing with AFS. As such, one of the key questions was whether design engineers needed help when designing with AFS. The survey shows that 32 out of 65 respondents $(49 \%)$ need support. 18 participants $(28 \%)$ responded that they did not need support, while 15 participants $(23 \%)$ could not answer this question. The result is shown in Figure 8.

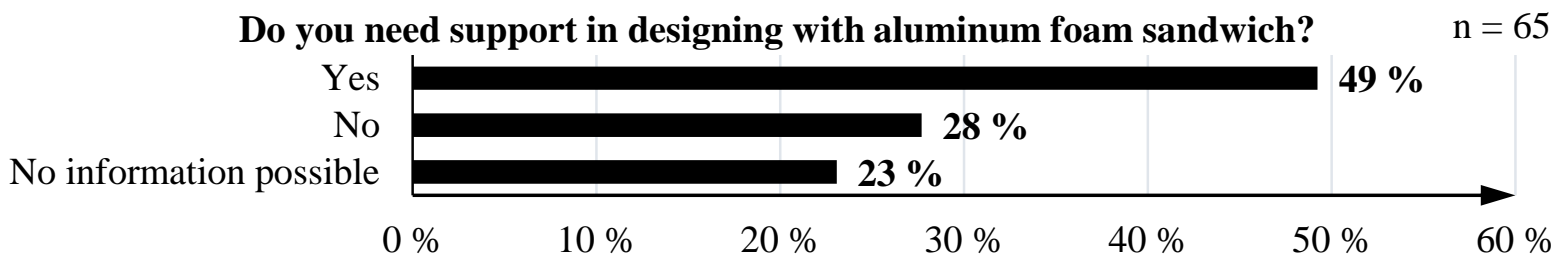

Figure 8. Need for support in designing with aluminum foam sandwich 
Looking only at the results of those participants who are currently using or have used AFS, the following result is obtained. 17 participants have used the material in previous projects, while six of them need support. This means that $35 \%$ of these experts still need help in designing with aluminum foam sandwich. Only half (53\%, 9 people) of those who already use the material do not require any further support. Two participants could not provide any information.

In a further free-text question, users were specifically asked which information was missing and how designing with aluminum foam sandwich could be simplified. The most frequently given responses were:

- Design catalogue, design guidelines, design specifications, manual as a use guide, design for manufacturability

- Overview of processing options

- Suitable joining techniques for various requirements with advantages and disadvantages

- Reference applications

- Overview of the potentials of the use of the material, suitable fields of application, methodology for optimal use

- Calculation specifications, calculation norms, qualified strength calculation

- Simulation, topology, material maps

The first point (design catalogue, design guidelines etc.) was mentioned by more than half of the participants.

When asked whether a document or platform with the appropriate material properties and design notes could be a support method for designing with AFS, $82 \%$ answered with "Yes" (68\%) or "Rather yes" (14\%), as shown in Figure 9 on the left. Only one participant (2\%) indicated that such a document would have no benefit for him. A similar distribution can be seen in the answers to the question of whether the participants in the survey would use such a document or platform. Here, $57 \%$ were in favor of clear use, while $14 \%$ were likely to use it and $18 \%$ ticked "Maybe" as their answer (Figure 9 on the right side).

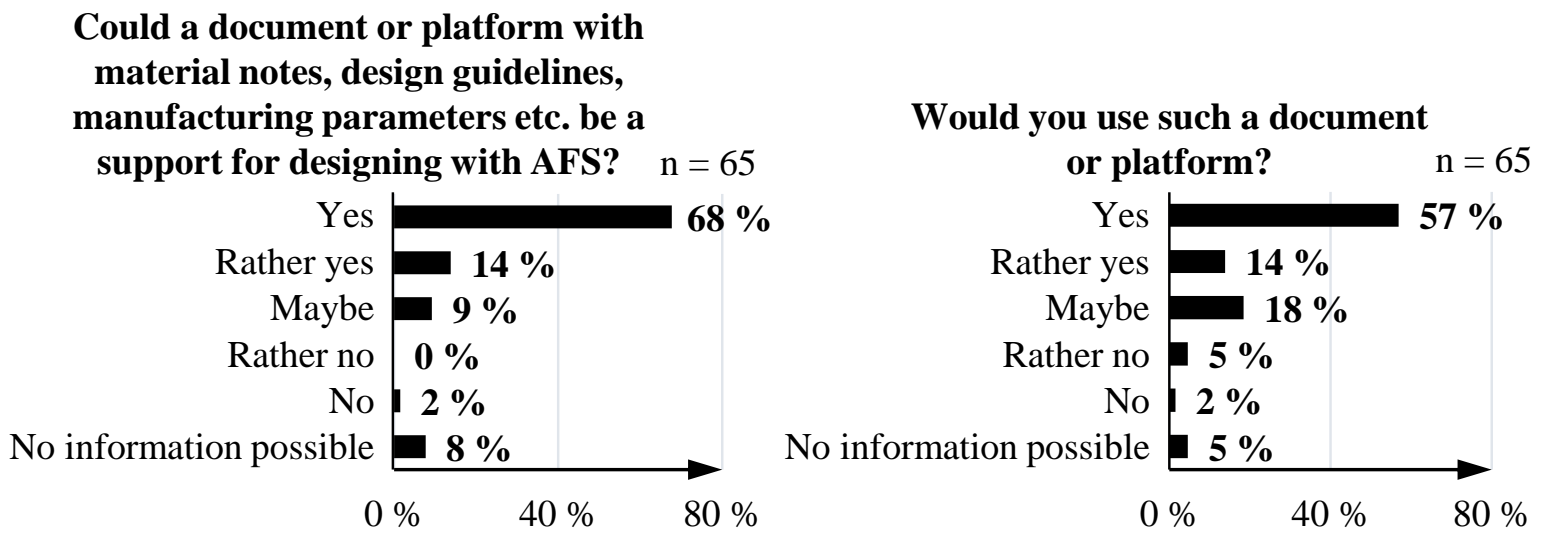

Figure 9. Requirement (left) and future use (right) of a document or platform for designing with aluminum foam sandwich

\section{Discussion}

In this section, the obtained results will be discussed. A survey was previously conducted to better understand the obstacles and the requirements for designing with aluminum foam sandwich. With the answers from the 65 participants of the survey, clear needs and a lack of knowledge can be identified. However, it should also be noted that these 65 respondents do not represent a holistic view of the industry.

The presented results show that most respondents are familiar with the material. Nevertheless, only about half of the participants consider AFS when selecting materials. In the end, only $18 \%$ of the participants currently use aluminum foam sandwich, with various reasons for this low use. The main obstacles to the use of AFS are presented in this paper: high cost, lack of design knowledge and missing reference applications. 
Similar obstacles to the use of metal foam, which were identified in a survey 20 years ago, are presented in the state of the art of this paper. By comparing these two surveys, the cost is still one of the main obstacles to the use of metal foam or aluminum foam sandwich, respectively. The lack of reference applications is also mentioned today with the same frequency as in the survey of Hipke and Wunderlich (2000).

One gratifying aspect is that the technical parameters and the availability of the material have improved, although the insufficient technical parameters and the lack of these parameters still contribute significantly to the fact that the use of the material today is still so low.

One issue that was not considered in the survey by Hipke and Wunderlich (2000) is the lack of design knowledge with the material. Besides the cost aspect, this lack of knowledge is most often described as an obstacle. The price will decrease with increasing acceptance and use of the material. However, the lack of design knowledge suggests a need for research. More than half of the participants in this survey criticize this lack of knowledge when designing with aluminum foam sandwich. From a methodological point of view, the lack of design knowledge and for example the lack of reference applications can be improved upon.

The evaluation of the free-text questions identifies a demand for methodological support. The participants suggested a design catalogue or design guideline several times as a possible support method. In addition to paper-based documents, further options also include an online platform with design recommendations and joining options or an online tool for calculation.

There are many ideas and opportunities for support, and the content and form for the most profitable support method needs to be elaborated. The result of the survey and the knowledge gained from this paper can be used to expand the research work in order to develop such support for designing with aluminum foam sandwich.

\section{Conclusion and outlook}

A survey in an industrial environment was carried out to identify the obstacles to the use of aluminum foam sandwich. The material is known and is ready for series production. Due to obstacles such as high costs and a lack of design knowledge or reference applications, designers do not use aluminum foam sandwich in the design process as much as they might.

The results of the survey and the discussion in this paper have shown that there is a need for design support. For example, the respondents mentioned several times that design guidelines or recommendations for practice would be desirable. In addition, an overview of reference applications and machining possibilities as well as information on joining techniques can minimize the obstacles and increase use.

This paper revealed the need for further efforts to make better use of the material. In the future, it will be necessary to investigate the content and form that optimal support might take. Initial approaches have already been discussed in this paper.

Development will take place on how to elaborate the optimal support for designing with aluminum foam sandwich with assistance from practical experts and manufacturers of the material. After developing such a design support method, it will need to be evaluated in practice.

\section{References}

Akiyama, S. et al. (1987), Foamed Metal and Method of Producing Same, U.S. Patent 4713277.

Banhart, J. (2018), "Production of Metal Foams", In: Beaumont, W. R. and Zweben, C. H. (Eds.), Comprehensive Composite Materials II, Vol. 4, Elsevier, pp. 347-363. https://doi.org/10.1016/B978-0-12803581-8.09976-8

Banhart, J. and Seeliger, H.-W. (2012), "Recent Trends in Aluminum Foam Sandwich Technology", Advanced Engineering Materials, Vol. 14 No. 12, pp. 1082-1087. https://doi.org/10.1002/adem.201100333

Banhart, J. et al. (1998), “Aluminiumschaum - Entwicklungen und Anwendungsmöglichkeiten”, IngenieurWerkstoffe, No. 7, pp. 43-45.

Banhart, J. et al. (2017), "Light-weighting in transportation and defence using aluminium foam sandwich structures", International Symposium on Light Weighting for Defence, Aerospace and Transportation, Indian Institute of Metals, Goa, November 11, 2017. 
Baumeister, J. (1990). Porous metal body production - involves compaction at low temperature followed by heating to near melting point of metal, German Patent DE 4018360.

Baumeister, J., Banhart, J. and Weber, M. (1994). Verfahren zur Herstellung eines metallischen Verbundwerkstoffs (Process for manufacturing metallic composite materials). German Patent DE 4426627.

Beichelt, C. (2005), Prozesskette AFS, Abschlussbericht Verbundforschungsprojekt, Wilhelm Karmann GmbH, Osnabrück, Germany. https://doi.org/10.2314/GBV:506587037

Binz, H. et al. (2018), "Konstruktion und Herstellung eines Auslegers aus Aluminiumschaum-Sandwich unter Anwendung der Fräskanttechnik", Konstruktion, No. 07-08/2018, pp. 78-82.

Florek, R. et al. (2014), "Injection molded plastics with aluminium foam core", Procedia Materials Science, Vol. 4, pp. 323-327. http://dx.doi.org/10.1016/j.mspro.2014.07.566

García-Moreno, F. (2016), "Commercial Applications of Metal Foams: Their Properties and Production", Materials, Vol. 9 No. 85. https://doi.org/10.3390/ma9020085

Hannemann, C. et al. (2018), "Manufacturing of foamable semin-finished products for aluminium foam sandwiches produced by extrusion", Presentation held at 5th Cellular Materials CellMAT, Bad Staffelstein, Germany, October 24-26, 2018. http://publica.fraunhofer.de/eprints/urn_nbn_de_0011-n-5185312.pdf

Havel metal foam GmbH (2019), Battery box for the future. [online] Available at: https://en.havel$\mathrm{mf} . c 0 \mathrm{~m} / \mathrm{solutions} /$ battery-box (accessed 26.09.2019).

Hipke, T. and Wunderlich, T. (2000), "Chancen und Hemmnisse für den Metallschaumeinsatz", Materialwissenschaft und Werkstofftechnik, Vol. 31 No. 6, pp. 396-399. https://doi.org/10.1002/15214052(200006)31:6\&1t;396::AID-MAWE396>3.0.CO;2-4

Hipke, T. (2002), Analyse, Bewertung und Eignung von Aluminiumschäumen für die Werkzeugmaschinenkonstruktion [PhD Thesis], Chemnitz University of Technology.

Hohlfeld, J., Hipke, T. and Schuller, F. (2018), "Sandwich Manufacturing with Foam Core and Aluminum Face Sheets - A New Process without Rolling”, Materials Science Forum, Vol. 993, pp. 3-10. https://doi.org/10. 4028/www.scientific.net/MSF.933.3

Hommel, P., Roth, D. and Binz, H. (2019), "Potenziale der Fräskanttechnik beim Fügen von Platten aus Aluminiumschaum-Sandwich", 5. Stuttgarter Symposium für Produktentwicklung (SSP), Stuttgart, Germany, May 15-16, 2019, pp. 43-52. http://dx.doi.org/10.18419/opus-10394

Metalfoam (2016), Metalfoam: Weltweit einzigartig - Die Lösung für Leichtbaukonstruktionen. [online] pohltec metalfoam GmbH. Available at https://www.metalfoam-afs.de/pdf/metalfoam_Broschuere_AFS_ 04032016_DE_Web.pdf (accessed 23.09.2019).

Nosko, M., Simančík, F. and Florek, R. (2010), "Reproducibility of aluminum foam properties: Effect of precursor distribution on the structural anisotropy and the collapse stress and its dispersion", Materials Science and Engineering A, Vol. 527 No. 21-22, pp. 5900-5908. http://dx.doi.org/10.1016/j.msea.2010.05.073

Orovčík, L. et al. (2016), "Effects of chemical composition on the pore structure and heat treatment on the deformation of PM aluminium foams 6061 and 7075", Metallic Materials, Vol. 54 No. 6, pp. 463-470. https://doi.org/10.4149/km_2016_6_463

Schmerler, R. et al. (2017), "Funktionsintegriertes Batteriegehäuse für Elektrofahrzeuge", Lightweight Design, No. 5/2017, pp. 32-37. https://doi.org/10.1007/s35725-017-0047-y

Schüler, P. (2016), Mechanische Eigenschaften und Versagensmechanismen offenzelliger AluminiumschaumStrukturen [PhD Thesis], Berlin University of Technology. http://dx.doi.org/10.14279/depositonce-5047

Schuller, F., Hohlfeld, J. and Hipke, T. (2017), "Sandwich manufacturing with foam core and coversheets out of aluminium - A new process without rolling", Presentation held at 10th International Conference on Porous Metals and Metallic Foams, MetFoam, Nanjing, China, September 15-17, 2017. http://publica.fraunhofer.de/eprints/urn_nbn_de_0011-n-4733025.pdf

Seeliger, H.-W. (2004), "Aluminium Foam Sandwich (AFS) Ready for Market Introduction”, Advanced Engineering Materials, Vol. 6 No. 6, pp. 448-451. https://doi.org/10.1002/adem.200405140

Seeliger, H.-W. (2011), "AFS-Weiterentwicklung erreicht Serienreife: Aluminiumschaum frisch vom Band", Aluminium Kurier News, No. 03/2011, p. 16.

Sviridov, A. (2011), Leichtbau mit Aluminiumschaumsandwich Prozessketten zur Herstellung von Bauteilen [PhD Thesis], Brandenburg University of Technology Cottbus. 